\title{
The Protective Effect of Autophagy on
} DNA Damage in Mouse SpermatocyteDerived Cells Exposed to $1800 \mathrm{MHz}$ Radiofrequency Electromagnetic Fields

\author{
Renyan Lia Mingfu Ma ${ }^{a} \quad$ Lianbing Lia Letian Zhao ${ }^{a} \quad$ Tianfeng Zhang ${ }^{a}$ \\ Xiaohan Gao ${ }^{a}$ Danyan Zhang ${ }^{a}$ Yijian Zhu ${ }^{a}$ Qiang Peng ${ }^{b} \quad$ Xue Luo \\ Minglian Wang ${ }^{\mathrm{d}}$
}

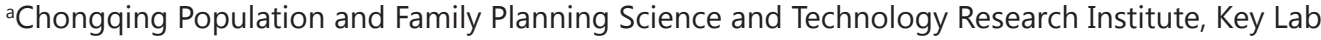
of Birth Defects and Reproductive Health of National Health and Family Planning Commission, Chongqing, ${ }^{b}$ Beibei District of Chongqing Municipal Public Security Bureau of Interpol detachment, Chongqing, 'Department of Tropical Medicine, College of Military Preventive Medicine, Army Medical University, Chongqing, ${ }^{\mathrm{C} C o l l e g e}$ of Life Science and Bioengineering, Beijing University of Technology, Chaoyang District, Beijing, China
\end{abstract}

\section{Key Words}

Radiofrequency electromagnetic fields - Melatonin - Oxidative stress - DNA damage • Autophagy

\begin{abstract}
Background/Aims: The effects of exposure to radiofrequency electromagnetic fields (RFEMFs) on the male reproductive system have raised public concern and studies have shown that exposure to RF-EMFs can induce DNA damage and autophagy. However, there are no related reports on the role of autophagy in DNA damage in spermatocytes, especially after exposure to RF-EMFs. The aim of the present study was to determine the mechanism and role of autophagy induced by RF-EMFs in spermatozoa cells. Methods: Mouse spermatocyte-derived cells (GC-2) were exposed to RF-EMFs $4 \mathrm{~W} / \mathrm{kg}$ for $24 \mathrm{~h}$. The level of reactive oxygen species (ROS) was determined by ROS assay kit. Comet assay was utilized to detect DNA damage. Autophagy was detected by three indicators: LC3II/LC3I, autophagic vacuoles, and GFP-LC3 dots, which were measured by western blot, transmission electron microscopy, and transfection with GFP-LC3, respectively. The expression of the molecular signaling pathway AMP-activated protein kinase (AMPK)/mTOR was determined by western blot. Results: The results showed that RF-EMFs induced autophagy and DNA damage in GC-2 cells via ROS generation, and the autophagy signaling pathway AMPK/mTOR was activated by ROS generation. Furthermore,
\end{abstract}

Renyan Li and Mingfu Ma contributed equally to this work.

\footnotetext{
Xue Luo Department of Tropical Medicine, College of Military Preventive Medicine Army Medical University, Chongqing;

and Minglian Wang College of Life Science and Bioengineering, Beijing University of Technology, Beijing, (China)

Fax+86-23-67867492, E-Mail luoxuecq@hotmail.com mlw@bjut.edu.cn
}

\section{KARGER}


following inhibition of autophagy by knockdown of AMPK $\alpha$, increased DNA damage was observed in GC-2 cells following RF-EMFs exposure, and overexpression of AMPK $\alpha$ promoted autophagy and attenuated DNA damage. Conclusions: These findings demonstrated that the autophagy which was induced by RF-EMFs via the AMPK/mTOR signaling pathway could prevent DNA damage in spermatozoa cells.

(C) 2018 The Author(s)

Published by S. Karger AG, Basel

\section{Introduction}

Wireless mobile phone communication has become ubiquitous worldwide. The radiation frequency emitted from mobile phones and their base station antennae ranges from 900$1800 \mathrm{MHz}$ for the Global System for Mobile Communications [1], which belongs to hyperfrequency electromagnetic fields (EMFs) [2]. The extensive use of mobile phones has been accompanied by possible adverse effects on human health, especially the male reproductive system. A number of recent studies have revealed a possible association between mobile phone use and impaired male reproduction [3-6]. However, the mechanisms of mobile phone use-induced male reproductive disorders remain obscure.

A previous study showed that the energy level associated with EMFs exposure is not sufficient to cause direct DNA damage, and it has been suggested that oxidative stress could be a key factor [7]. Spermatozoa are uniquely sensitive to oxidative stress and have a limited capacity for DNA repair [8]. Several reports have indicated that EMFs enhance free radical activity in spermatozoa and induce DNA damage $[9,10]$. Recently, it was reported that one of the contributory factors involved in male reproductive disorders is spermatozoa DNA damage, which has been found to be associated with reduced rates of fertilization, poor embryonic development, high rates of miscarriage and an increased incidence of morbidity in the offspring, including childhood cancer $[11,12]$. Therefore, it is essential to prevent sperm DNA damage due to RF-EMFs exposure.

Autophagy is a catabolic process that facilitates nutrient recycling via degradation of damaged organelles and proteins mediated by lysosomes [13], which contributes directly to cell metabolism and energy regulation [14], and is essential for the maintenance of cellular homeostasis [15]. RF-EMFs-induced autophagy can balance cellular homeostasis to protect cells from severe adverse biological consequences [16]. C57BL/6 mice were exposed to 835 MHz RF-EMFs at a specific absorption rate (SAR) of $4.0 \mathrm{~W} / \mathrm{kg}$ for $5 \mathrm{~h} /$ day over 12 weeks, and the data suggested that autophagy may act as a protective pathway for neuronal cells during radiofrequency exposure [17]. A previous study on the male reproductive system also indicated that autophagy may play an important role in preventing apoptotic cell death in spermatozoa following exposure to $1800 \mathrm{MHz}$ Global System for Mobile Communication (GSM) signals in GSM-Talk mode at a SAR value of $4 \mathrm{~W} / \mathrm{kg}$ for $24 \mathrm{~h}$ [18]. However, the role of autophagy in DNA damage induced by $1800 \mathrm{MHz}$ RF-EMFs has not been established.

The purpose of the present study was to determine the exact mechanism by which RFEMFs trigger autophagy and the role of autophagy plays in the DNA damage response to RF-EMFs-induced ROS production. For this purpose, DNA damage and autophagy induced by RF-EMFs and the role of ROS in this process were investigated in mouse spermatocytederived cells. We also examined the role of AMPK/mTOR signaling pathway-mediated autophagy following RF-EMFs exposure. The findings provided evidence of which signaling pathway triggers autophagy and the role of autophagy in DNA damage induced by RF-EMFs in spermatozoa cells.

\section{Materials and Methods}

Cell culture and treatment

The mouse spermatocyte-derived cell line, GC-2spd (ts) (GC-2), was obtained from the American Type Culture Collection (ATCC; Rockville, MD, USA). The GC-2 cells were cultured in a $5 \% \mathrm{CO}_{2}$ humidified 


\section{Cellular Physiology Cell Physiol Biochem 2018;48:29-41 and Biochemistry Published online: July 11, $2018 \quad \begin{aligned} & \text { DOI: 10.1159/000491660 } \\ & \text { www.karger.com/cpb }\end{aligned}$ \\ Li et al.: Autophagy Prevents DNA Damage}

atmosphere at $37^{\circ} \mathrm{C}$ and maintained in high-glucose Dulbecco's modified Eagle's medium (DMEM; SH30022.01, HyClone, Logan, UT, USA) containing 10\% fetal bovine serum (P40-47500, PAN-Biotech, Aidenbach, Germany) and 1\% penicillin-streptomycin (SV30010, Hyclone, Logan, UT, USA).

\section{$R F$-EMFs exposure system}

The RF-EMFs exposure system was kindly built and provided by the Foundation for Information Technologies in Society (IT'IS Foundation, Zurich, Switzerland), as described in a previously published comparative study on this topic [10]. The RF exposure system primarily consisted of the following four parts: a RF generator, an arbitrary function generator, a narrow band amplifier and two rectangular waveguides. One waveguide was used for exposure, and the other waveguide was used for sham exposure; both waveguides were placed inside a $\mathrm{CO}_{2}$ incubator. The sensors and fans in the exposure system were connected to a computer that monitored the SAR value during exposure and maintained a constant temperature and environment for the waveguides $\left(37^{\circ} \mathrm{C}, 5 \% \mathrm{CO}_{2} / 95 \%\right.$ atmospheric air). Petri dishes were placed in the $\mathrm{H}$-field maxima and exposed to a polarized E-field (an electric field perpendicular to the $\mathrm{H}$-field); in total, 6 dishes were simultaneously exposed in this manner. The system was operated at a steady frequency of $1800 \mathrm{MHz}$. It is well established that the SAR variability of this system is below 6\%, with a temperature rise of $0.03^{\circ} \mathrm{C} /(\mathrm{W} / \mathrm{kg})$ in the average SAR value following exposure of mono-layer cells and an excellent SAR efficiency of above $50(\mathrm{~W} / \mathrm{kg}) / \mathrm{W}$; for mono-layer cells, the temperature change is uniformly distributed with no localized temperature "hot spots" [19], and the temperature difference between the RF-exposed and sham-exposed chambers does not exceed $0.1^{\circ} \mathrm{C}$. To perform double-blind experiments, the computer randomly determines which of the two waveguides was exposed in each trial. All the exposure conditions and monitor data were encrypted in a file, which was transmitted to the IT'IS Foundation via e-mail and decoded by the Foundation following data analysis.

\section{Cell exposure procedure}

Cells were seeded into $35 \mathrm{~mm}$ Petri dishes (153066, Thermo Fisher Scientific, NY, USA) at a density of $1 \times 10^{5} / \mathrm{ml}$ before exposure. Twenty-four hours after cell seeding, the culture medium was renewed, and the cells were exposed to $1800 \mathrm{MHz}$ GSM-Talk signals for $24 \mathrm{~h}$ with an intermittent cycle of $5 \mathrm{~min}$ on and 10 min off for the indicated time intervals. To determine the SAR-related effects of RF exposure, the cells were randomly divided into the following groups: (1) Sham exposure; (2) $1 \mathrm{~W} / \mathrm{kg}$; (3) $2 \mathrm{~W} / \mathrm{kg}$ and (4) 4 $\mathrm{W} / \mathrm{kg}$. High-intensity RF-EMFs exposure at SAR $\geqslant 4 \mathrm{~W} / \mathrm{kg}$ causes thermal effects [20]. Each cell culture experiment was repeated at least three times.

\section{Alkaline and neutral comet assay}

The alkaline comet assay was performed to detect the DNA single- and double-strand breaks as well as alkali labile sites, and the neutral comet assay was carried out to detect DNA double-strand breaks [21]. The alkaline comet assay was performed using a Comet Assay Reagent Kit (4250-050-K, Trevigen, USA) after exposure to RF-EMFs at 1,2 , or $4 \mathrm{~W} / \mathrm{kg}$ for $24 \mathrm{~h}$ as described previously [10]. Following exposure to RFEMFs, the cells were detached by trypsin digestion. The cell suspension from each dish, with a density of 3-5 $\times 10^{5} \mathrm{cells} / \mathrm{ml}$, was embedded in pre-warmed $\left(37^{\circ} \mathrm{C}\right)$ low melting point agarose $(" 4250-050-02)$ at a ratio of 1:10 (v/v) on Trevigen CometSlides ( $\left.{ }^{\sharp} 4250-050-03\right)$. After the slides had been prechilled at $4^{\circ} \mathrm{C}$ for $30 \mathrm{~min}$, they were immersed in lysis solution ( $\left.{ }^{\#} 4250-050-01\right)$ for $1 \mathrm{~h}$ at $4^{\circ} \mathrm{C}$. In the alkaline comet assay, unwinding in an alkaline unwinding solution (200 mM NaOH, 1 mM EDTA pH 10 ("4250-050-04), pH >13) for 20 min was undertaken at room temperature, and the slides were then subjected to $4^{\circ} \mathrm{C}$ alkaline electrophoresis solution $(200 \mathrm{mM} \mathrm{NaOH}, 1 \mathrm{mM}$ EDTA pH $8, \mathrm{pH}>13)$ at $1 \mathrm{~V} / \mathrm{cm}$ for $40 \mathrm{~min}$. In the neutral comet assay, following lysis of the cells, they were subjected to $4{ }^{\circ} \mathrm{C}$ neutral electrophoresis solution $(1 \mathrm{M}$ Tris Base, $3 \mathrm{M}$ Sodium Acetate, $\mathrm{pH}$ 9) at $1 \mathrm{~V} / \mathrm{cm}$ for $40 \mathrm{~min}$. After electrophoresis, the slides were then immersed twice in $\mathrm{dH}_{2} \mathrm{O}$ for $5 \mathrm{~min}$ each and in $75 \%$ ethanol for $5 \mathrm{~min}$. The resulting comets were visualized with diluted SYBR ${ }^{8}$ Green I (Invitrogen) and examined using a fluorescence microscope (Eclipse Ti-SR, Nikon, Japan) at 200 magnification. The levels of DNA damage were calculated as follows: (a) Tail DNA (\%), which is a measure of the pixel intensity was expressed as a percentage, and indicated the ratio of DNA present in the tail to the total DNA content. (b) Tail length $(\mu \mathrm{m})$, which is the distance from the end of DNA migration to the nuclear core; images from at least 100 nucleoli in each sample were scored in at least three independent experiments. All comet parameters were assessed using a computer-based image analysis system (Comet Assay Software Project, CASP Lab, Poland). 


\section{Cellular Physiology Cell Physiol Biochem 2018;48:29-41 and Biochemistry Published \begin{tabular}{l|l} 
DOI: 10.1159/000491660 & $\begin{array}{l}\text { C } 2018 \text { The Author(s). Published by S. Karger AG, Basel } \\
\text { www.karger.com/cpb }\end{array}$
\end{tabular}}

Li et al.: Autophagy Prevents DNA Damage

ROS generation assay

ROS were measured with the non-fluorescent probe 2', 7'-dichlorofluorescein diacetate (DCFH-DA) (Beyotime Company, China) according to a previous study [22, 23]. Briefly, after the cells were treated with RF-EMFs $(1,2$, or $4 \mathrm{~W} / \mathrm{kg}$ ) for $24 \mathrm{~h}$, the culture medium was removed and the cells were washed three times with PBS. The cells were then exposed to $10 \mu \mathrm{M}$ DCFH-DA for $20 \mathrm{~min}$, washed, and then scraped into $1 \mathrm{ml}$ of PBS. The fluorescence was read at $495 \mathrm{~nm}$ for excitation and $535 \mathrm{~nm}$ for emission with a microplate reader (Enspire, PerkinElmer, USA).

\section{Cell viability determination}

The cytotoxicity of RF-EMFs in GC-2 cells was assessed using a Cell Counting Kit-8 (Beyotime Company, China) assay. Cells were exposed to RF-EMFs (1, 2, or $4 \mathrm{~W} / \mathrm{kg}$ ) for $24 \mathrm{~h}$, the culture medium was removed and the cells were washed three times with PBS. The cells were then seeded in 96-well flat-bottomed plates at a density of 5, 000 cells/well and incubated with CCK-8 solution for another $2 \mathrm{~h}$ according to the instructions in the technical manual. Cell viability was expressed as the optical density detected at $450 \mathrm{~nm}$ using a microplate reader (Enspire, PerkinElmer, USA).

\section{Determination of autophagic cells}

Cells were seeded on $35 \mathrm{~mm}$ Petri dishes (153066, Thermo Fisher Scientific, NY, USA) at a density of $5 \times 10^{4} / \mathrm{ml}$. To assess autophagy, the cells were transfected with Premo ${ }^{\mathrm{TM}}$ Autophagy Sensor LC3B-GFP (BacMam 2.0) (P36235, Thermo Fisher Scientific, NY, USA) for $24 \mathrm{~h}$ before exposure to RF-EMFs. Following RF-EMFs exposure, the cells were observed using a fluorescent microscope (Eclipse Ti-SR, Nikon, Japan). Cells with more than twenty GFP-LC3 dots were considered to be autophagic, and were quantified [18].

\section{Transmission electron microscopy (TEM)}

For the transmission electron microscopy studies, cells were exposed to RF-EMFs $(1,2$, or $4 \mathrm{~W} / \mathrm{kg}$ ) for $24 \mathrm{~h}$, then harvested and washed twice with PBS ( $\mathrm{pH} \mathrm{7.4)} \mathrm{at} \mathrm{room} \mathrm{temperature,} \mathrm{and} \mathrm{fixed} \mathrm{with} 2.5 \%$ glutaraldehyde. The cells were then washed three times with PBS and fixed with 1\% osmic acid for 2-3 h, washed three times with PBS, dehydrated, embedded in paraffin, cut into sections $70 \mathrm{~nm}$ thick using an Ultra-thin slicing machine (Leica EM UC6, Leica Microsystems, Wetzlar and Mannheim, Germany), and then stained with Uranyl acetate-lead citric. The cells were then observed using TEM (JEM1230, JEOL Ltd., Tokyo, Japan) to detect autophagic vacuoles.

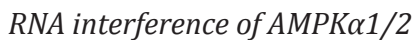

AMPK $\alpha 1 / 2$ siRNA (m) (sc-45313) and a control nonspecific siRNA (sc37007) were purchased from Santa Cruz Biotechnology as described previously [24]. Transfection of siRNAs using Attractene Transfection reagent (301005, Qiagen, Germany) was performed according to the manufacturer's instructions. Fortyeight hours after transfection, the cells were treated with RF-EMFs ( $4 \mathrm{~W} / \mathrm{kg}$ ) for $24 \mathrm{~h}$, and then collected and processed for immunoblotting.

\section{Plasmid transfection of AMPK $1 / 2$}

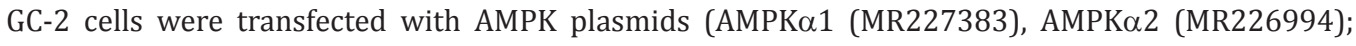
Origene, USA) using HiPerFect Transfection reagent (301705, Qiagen, Germany) according to the manufacturer's instructions and a previous study [25], and cultured for $24 \mathrm{~h}$. Empty vector (PS100001, Origene, USA) transfected cells were generated in parallel. The cells were treated with RF-EMFs $4 \mathrm{~W} / \mathrm{kg}$ for $24 \mathrm{~h}$, and then collected for immunoblotting.

\section{Western blot}

After treatment, the GC-2 cells were harvested and lysed in cell lysis buffer (P0013B, Beyotime Company, Shanghai, China) on ice, and centrifuged for $15 \mathrm{~min}$ at $12,000 \mathrm{~g}$ and $4^{\circ} \mathrm{C}$. The supernatant was collected and heated at $100^{\circ} \mathrm{C}$ for $10 \mathrm{~min}$, and the protein concentrations were determined using a BCA Protein Assay Kit (P0010, Beyotime Company, Shanghai, China). The procedure was described as previously $[26,27]$. Identical amounts of protein $(60 \mu \mathrm{g})$ from each sample were loaded and run on $12 \%$ SDS-PAGE gels and transferred to PVDF membranes (Merck Millipore, Billerica, MA, USA) by Semi-Dry Electrophoretic Transfer (Bio-Rad, USA). The membranes were blocked with 5\% non-fat milk in Tris-buffered saline with 


\section{Cellular Physiology Cell Physiol Biochem 2018;48:29-41 and Biochemistry Published online: July $11,2018 \quad \begin{aligned} & \text { DOI: 10.1159/000491660 } 2018 \text { The Author(s). Published by S. Karger AG, Basel } \\ & \text { www.karger.com/cpb }\end{aligned}$ \\ Li et al.: Autophagy Prevents DNA Damage}

$0.1 \%$ Tween 20 (TBST) at room temperature for $1 \mathrm{~h}$, and then incubated overnight at $4^{\circ} \mathrm{C}$ with antibodies against LC3 (1:1000; Sigma, L7543), $\gamma$-H2AX (Ser139) (1:1000; CST, 9718p), P62 (1:1000; CST, 5114T),

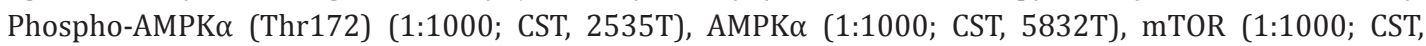
2972), p-mTOR (ser2448) (1:1000; CST, 5536), and GAPDH (1:1000; CST, 5174S). The membranes were subsequently washed with TBST, and incubated with HRP-conjugated secondary antibodies for $1 \mathrm{~h}$ at room temperature. After washing with TBST, the immunoblots were visualized by chemiluminescence using HRP substrate (WBKLS0500, Merck Millipore, Billerica, MA, USA). GAPDH was used to ensure equal protein loading.

\section{Statistical analysis}

All calculations and statistical analyses were generated using SPSS version 16.0. Significant differences between the groups for each experimental test condition were evaluated by one-way analysis of variance (ANOVA). The data, from at least three independent experiments, were expressed as the mean and standard deviation (SD). $P$ $<0.05$ was considered significant.

\section{Results}

DNA damage was induced by $R F-$ EMFs exposure

To investigate whether DNA damage is involved in the cytotoxicity of RF-EMFs, the gold marker of DNA double-strand damage, $\gamma$-H2AX, was determined by the alkaline comet assay (DNA single- and double-strand breaks as well as alkali labile sites) and neutral comet assay (DNA double-strand breaks) after exposure to RF-EMFs. The alkaline comet assay showed that DNA damage was significantly induced by RF-EMFs $4 \mathrm{~W} / \mathrm{kg}$ for 24 $\mathrm{h}$, but DNA damage was not detected by the neutral comet assay or the expression level of $\gamma$-H2AX (Fig. 1A and $B$ ). In addition, cell viability was significantly reduced in the RF-EMFs $4 \mathrm{~W} / \mathrm{kg}$ group compared with the sham exposure group (Fig. 1C).

DNA damage was induced by RF-EMFs exposure via ROS generation

The level of intracellular ROS, which was examined using the ROS specific fluorescent dye DCFH-DA, was significantly increased following exposure to RF-EMFs compared

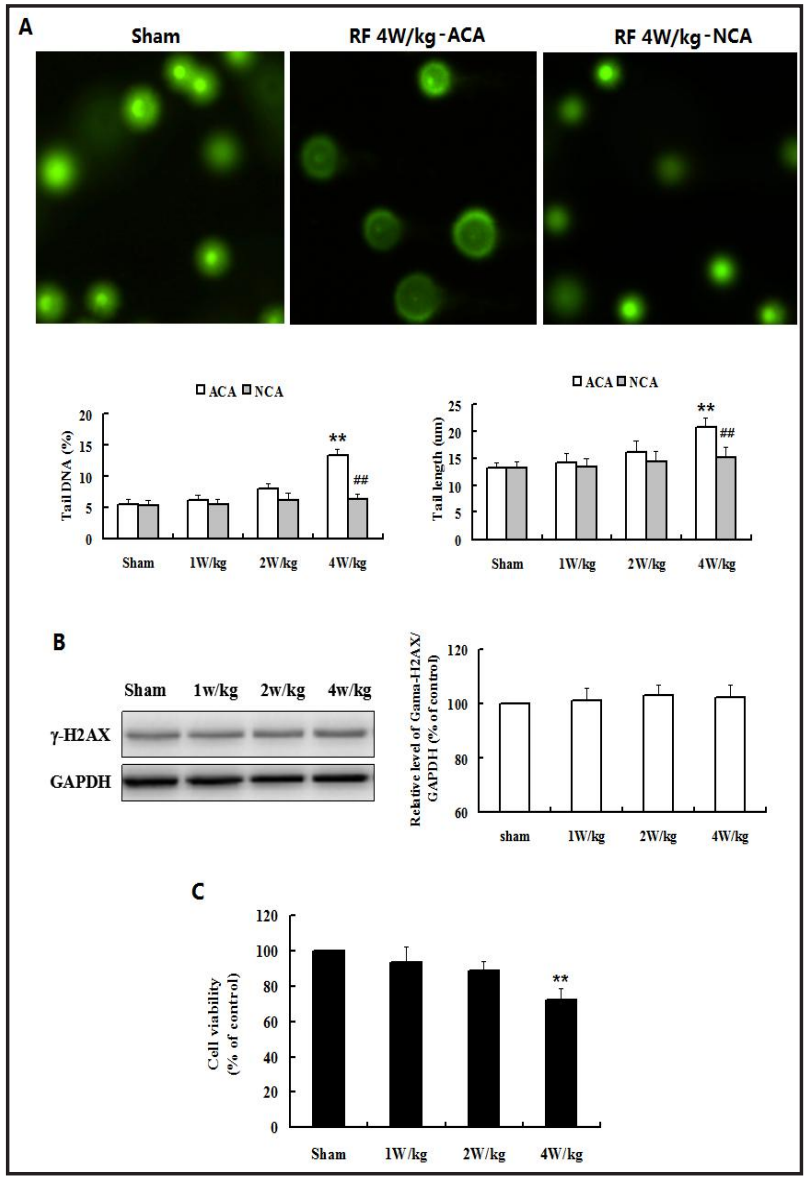

Fig. 1. DNA damage was induced by RF-EMFs exposure in GC-2 cells. (A) DNA damage was detected by alkaline and neutral comet assay after exposure to RF-EMFs 1, 2, 4W/ $\mathrm{kg}$ for $24 \mathrm{~h}$, the tail DNA and tail length were calculated (the magnification was 100×). (B) A representative immunoblot and quantification analysis of $\gamma$-H2AX after GC-2 cells exposure to RF-EMFs 1, 2, 4W/kg for 24h, GAPDH used as an internal standard for protein loading. (C) The cell viability was detected by cck8 kit after exposure to RF-EMFs 1, 2, 4W/ $\mathrm{kg}$ for $24 \mathrm{~h}$. The results were expressed as a percentage of the control, which was set at $100 \%$. The values were presented as the means $\pm \mathrm{SD},{ }^{* *} \mathrm{P}<0.01$ versus the control group. ACA: alkaline comet assay; NCA: neutral comet assay. ${ }^{\#} \mathrm{P}<0.01$ ACA vs NCA group. 
with the sham exposure group (Fig. $2 \mathrm{~A})$, and pretreatment with the antioxidant melatonin $2 \mathrm{~h}$ prior to RF-EMFs treatment significantly reduced ROS levels compared with RF-EMFs treatment alone (Fig. 2A). Pretreatment with melatonin significantly decreased RF-EMFsinduced DNA damage, and both tail DNA and tail length were significantly decreased in the RF-EMFs group compared with the sham exposure group (Fig. 2B).

\section{Autophagy was induced by RF- EMFs exposure}

To investigate whether autophagy is induced by RF-EMFs, we examined the processing of LC3-I to LC3-II by western blot assay, a hallmark of autophagy, in RFEMFs-treated GC-2 cells. RF-EMFs treatment increased the protein levels of LC3-II in a dose-dependent manner (Fig. 3A). P62 serves as a link between LC3 and ubiquitinated substrates and a reduction in the amount of p62 reflects an increase in autophagic degradation [28].

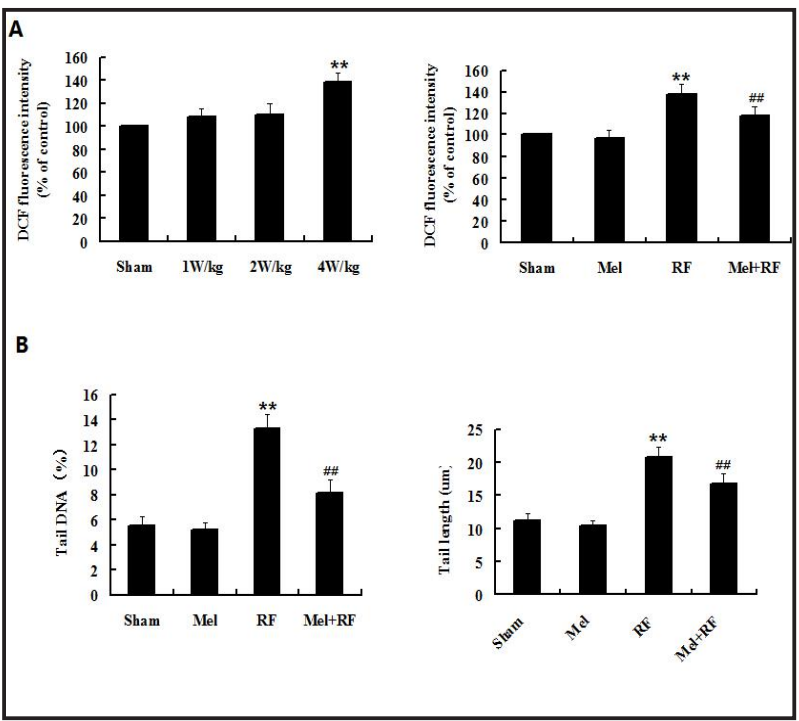

Fig. 2. DNA damage was induced by RF-EMFs exposure via ROS generation. (A) DCF fluorescence was detected after GC- 2 cells were exposed to RF-EMFs $1,2,4 \mathrm{~W} / \mathrm{kg}$ for $24 \mathrm{~h}$, and pretreated with or without melatonin. (B) DNA damage was detected after GC-2 Cells were pretreated with or without melatonin $(10 \mu \mathrm{M})$ for $2 \mathrm{~h}$ then exposed to RF-EMFs $4 \mathrm{~W} /$ $\mathrm{kg}$ for $24 \mathrm{~h}$, the tail DNA and tail length were calculated. The results were expressed as a percentage of the control, which was set at $100 \%$. The values were presented as the means \pm $\mathrm{SD},{ }^{* *} \mathrm{P}<0.01$ versus the control group, ${ }^{\# \#} \mathrm{P}<0.01$ vs. the RFEMFs $4 \mathrm{~W} / \mathrm{kg}$ group. Immunoblot analysis showed that RF-EMFs treatment decreased the level of p62 (Fig. 3A). Evidence of RF-EMFs-induced autophagy was provided by direct observation of the formation of autophagosomes using electron microscopy (Fig. 3B). To further confirm that RF-EMFs induce autophagy in GC-2 cells, these cells were transiently transfected with GFP-LC3 and then treated with RF-EMFs $4 \mathrm{~W} / \mathrm{kg}$ for $24 \mathrm{~h}$. Fluorescence microscopic examination showed the characteristic punctate fluorescent pattern of GFP-LC3, indicating autophagosome formation and the occurrence of autophagy (Fig. 3C). The percentage of GFP-LC3 transfected cells with punctate fluorescence in RF-EMFs-treated cells was significantly higher than that in the control (Fig. 3C).

Autophagy was induced by RF-EMFs exposure via ROS generation and activated by AMPK/ mTOR

Cells were treated with melatonin $2 \mathrm{~h}$ prior to RF-EMFs exposure to investigate whether autophagy was induced by RF-EMFs via ROS generation and the autophagy signaling pathway was also determined (Fig. 4). The results showed that the phosphorylation levels of AMPK significantly increased and p-mTOR significantly decreased after RF-EMFs exposure (Fig. 4A), and pretreatment with melatonin decreased the expression of LC3II/LC3I, and prevented activation of the AMPK/mTOR signaling pathway (Fig. 4B).

\section{Inhibition of autophagy by knockdown AMPKa was involved in increased DNA damage by} RF-EMFs

Autophagy was induced by RF-EMFs treatment. However, whether autophagy plays a role in DNA damage induced by RF-EMFs has not been reported. To determine the role of AMPK in RF-EMFs-induced DNA damage and autophagy, AMPK was silenced by siRNA (Fig. 5). Silencing of AMPK significantly reversed RF-EMFs-induced expression of p-mTOR and 


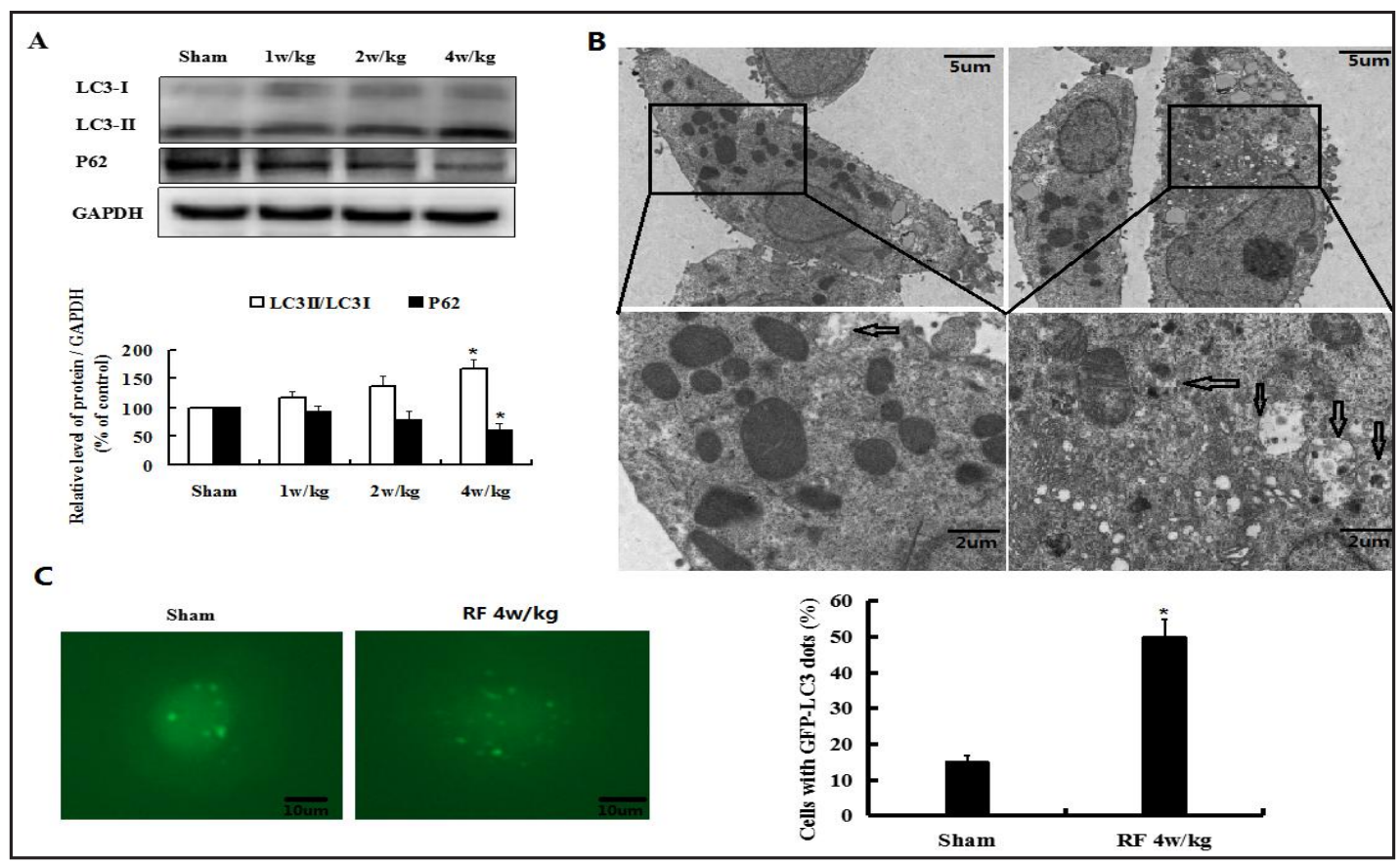

Fig. 3. Autophagy was induced by RF-EMFs exposure. (A) A representative immunoblot and quantification analysis of LC3 and P62 as assayed after GC-2 cells were exposed to RF-EMFs 1, 2, 4W/kg for 24h. GAPDH used as an internal standard for protein loading. (B) Transmission electron microscopy revealed an increased number of autophagic vacuoles with or without exposure to RF-EMFs 4W/kg for 24h. (C) The formation of GFP-LC3 puncta was examined by fluorescence microscope and was quantified after GC-2 cells were exposed to RF-EMFs $4 \mathrm{~W} / \mathrm{kg}$ for 24 hours (scale bar $=10 \mu \mathrm{m}$ ). The results were expressed as a percentage of the control, which was set at $100 \%$. The values were presented as the means $\pm \mathrm{SD},{ }^{* *} \mathrm{P}<0.01$ versus the control group, ${ }^{\# \# ~} \mathrm{P}<0.01$ vs. the RF-EMFs $4 \mathrm{~W} / \mathrm{kg}$ group.

Fig. 4. Autophagy was induced by RFEMFs exposure via ROS generation and activated by AMPK/mTOR. (A) AMPK activation and mTOR repression by RF-EMFs exposure to $4 \mathrm{~W} / \mathrm{kg}$ for 24h. (B) AMPK activation and mTOR repression were recovered by pretreated with melatonin $(10 \mu \mathrm{M})$ for $2 \mathrm{~h}$. A representative immunoblot and quantification analysis of p-ATM, ATM, p-AMPK, AMPK, p-mTOR, mTOR, LC3 and P62 as assayed after GC-2 cells were pretreated with or without melatonin $(10 \mu \mathrm{M})$ for $2 \mathrm{~h}$ then exposure to RF-EMFs $4 \mathrm{~W} / \mathrm{kg}$ for $24 \mathrm{~h}$. GAPDH used as an internal standard for protein loading. The results were expressed as a percentage of the control, which was set at $100 \%$. The values were presented as the means $\pm \mathrm{SD},{ }^{* *} \mathrm{P}<0.01$ versus the control group, ${ }^{\# \#} \mathrm{P}<0.01$ vs. the RF-EMFs $4 \mathrm{~W} / \mathrm{kg}$ group.

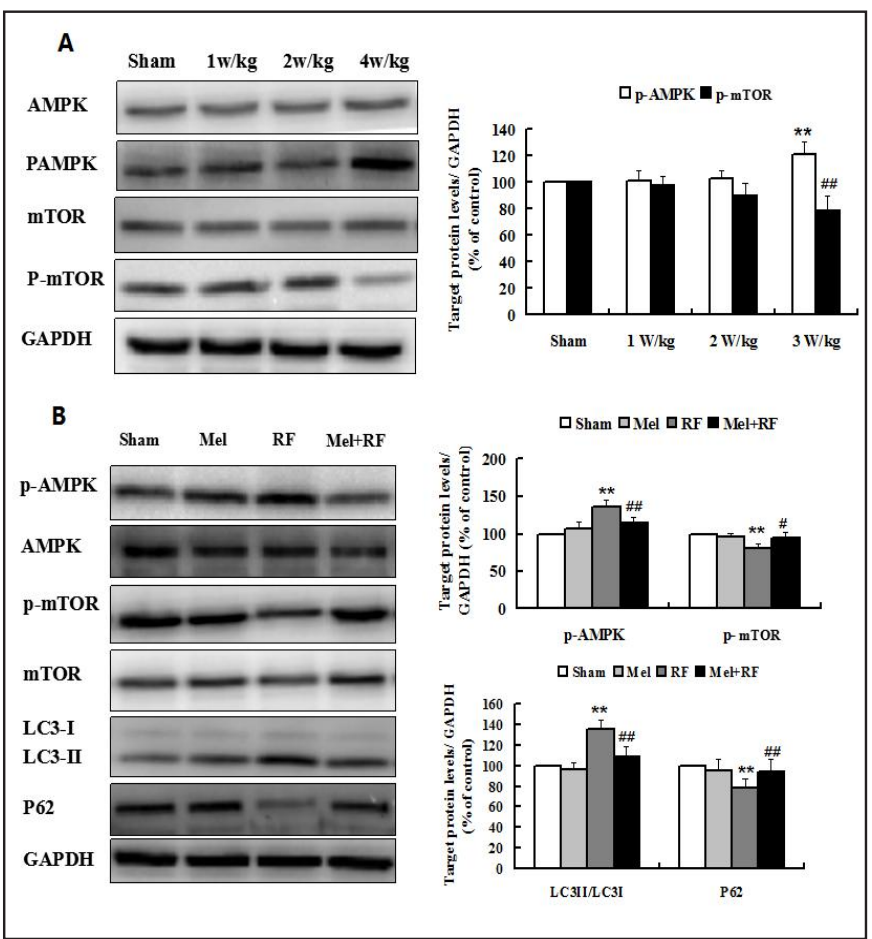


Fig. 5. AMPK $\alpha$ knockdown by siRNA suppressed autophagy and promoted DNA damage after exposure to RFEMFs $4 \mathrm{~W} / \mathrm{kg}$ for $24 \mathrm{~h}$ in GC-2 cells. (A) A representative immunoblot and quantification analysis of p-ATM, ATM, p-AMPK, AMPK, p-mTOR, mTOR, LC3 and P62 as assayed in GC-2 cells. (B) The quantification analysis of tail DNA and tail length as detected in GC-2 cells after knockdown AMPK $\alpha$ for $48 \mathrm{~h}$ then exposure to RF-EMFs $4 \mathrm{~W} / \mathrm{kg}$ for $24 \mathrm{~h}$. The results were expressed as a percentage of the control, which was set at $100 \%$. The values were presented as the means $\pm \mathrm{SD},{ }^{* *} \mathrm{P}<0.01$ versus the control group, \#\# $\mathrm{P}<0.01$ vs. the RF-EMFs $4 \mathrm{~W} / \mathrm{kg}$ group.

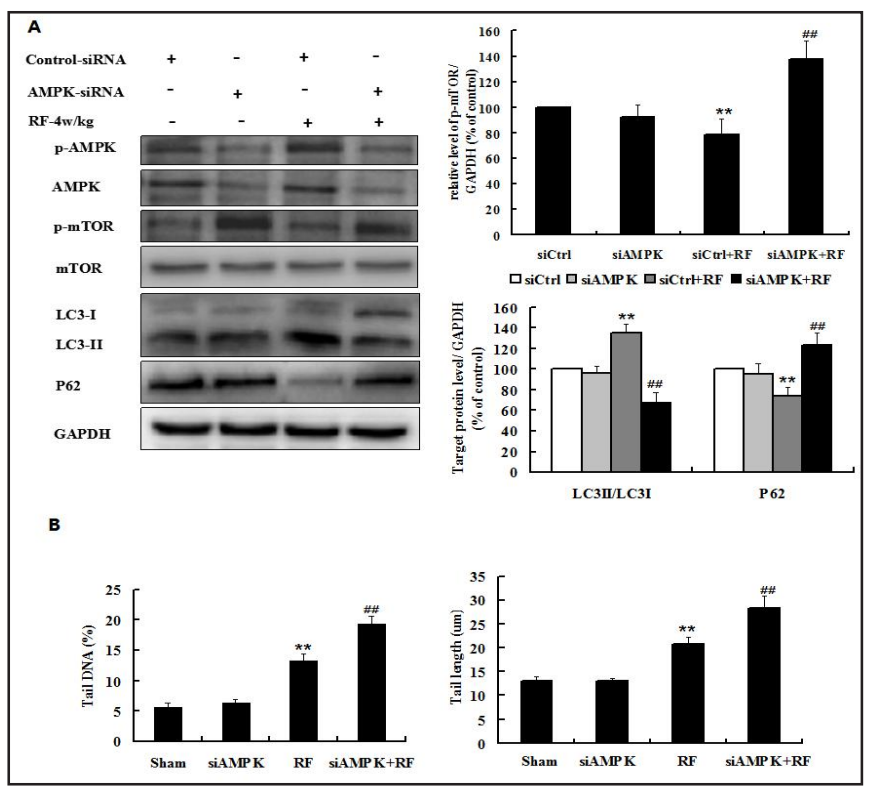

Fig. 6. Promotion of autophagy by over expression AMPK was involved in RF-EMFs decreased DNA damage. (A) A representative immunoblot and quantification analysis of p-ATM, ATM, p-AMPK, AMPK, p-mTOR, mTOR and LC3 as assayed in GC-2 cells. (B) The quantification analysis of tail DNA and tail length as detected in GC-2 cells after over expression AMPK $\alpha 2$ for $24 \mathrm{~h}$ then exposure to RF-EMFs $4 \mathrm{~W} / \mathrm{kg}$ for $24 \mathrm{~h}$. The results were expressed as a percentage of the control, which was set at $100 \%$. The values were presented as the means $\pm \mathrm{SD},{ }^{*} \mathrm{P}<0.01$ versus the control group, \#\# $\mathrm{P}<0.01$ vs. the RF-EMFs $4 \mathrm{~W} / \mathrm{kg}$ group.

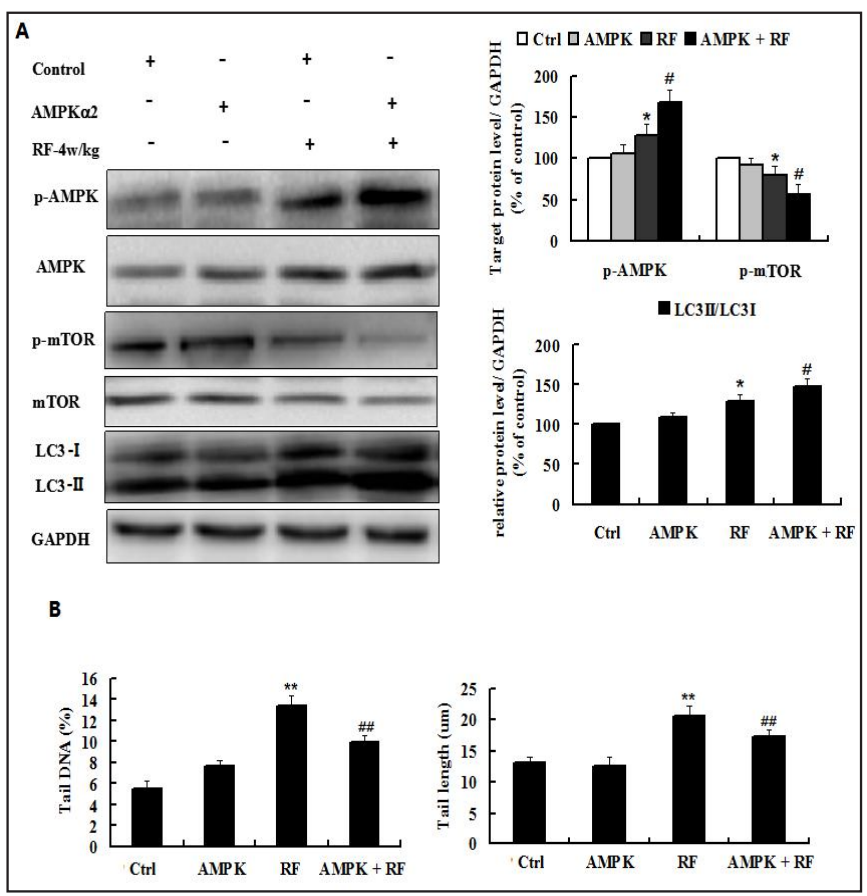

LC3II (Fig. 5A), and increased DNA damage (Fig. 5B). These results indicated that autophagy may protect cells from continuous DNA damage, and inhibition of autophagy could result in accumulation of DNA damage in GC-2 cells.

Promotion of autophagy following overexpression of AMPK $\alpha$ was involved in decreased DNA damage

To further confirm the role of AMPK in RF-EMFs-induced DNA damage and autophagy, AMPK was overexpressed using the AMPK $\alpha 1 / 2$ plasmid (Fig. 6). The results indicated that overexpression of AMPK $\alpha 2$ significantly decreased RF-EMFs-induced expression of p-mTOR and increased LC3II (Fig. 6A), and DNA damage was significantly attenuated following overexpression of AMPK $\alpha 2$ induced by RF-EMFs exposure (Fig. 6B). However, there was no 
significant difference between the group with AMPK $\alpha 1$ overexpression and the control group in terms of the expression of LC3II and DNA damage (data not shown). These results suggest that AMPK played a key role in promoting autophagy and DNA damage in response to RFEMFs in GC-2 cells. A summary of these findings is shown in Fig. 7.

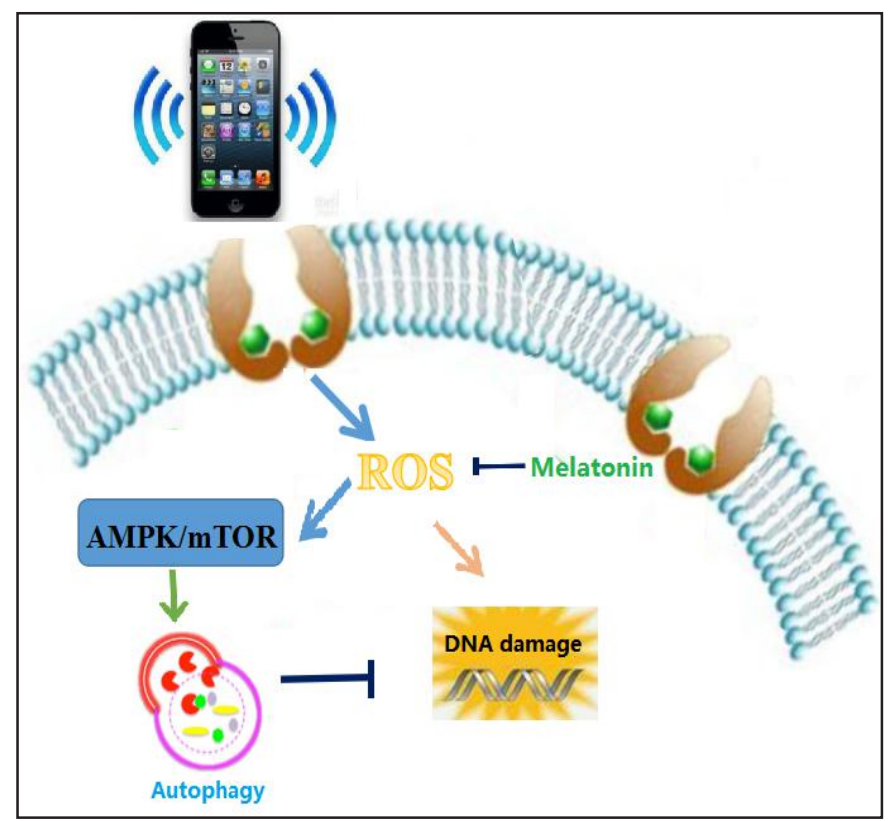

Fig. 7. Schematic showed signaling pathway AMPK/mTOR induction autophagy after RF-EMFs via ROS generation, and the autophagy could prevent DNA damage from RF-EMFs exposure. damage in mouse spermatocy cells at a SAR value of $4 \mathrm{~W} /$ $\mathrm{kg}$ for $24 \mathrm{~h}$ and this process was mediated by ROS. The antioxidant melatonin inhibited autophagy by suppressing RFEMFs-induced ROS generation. In addition, autophagy induced by RF-EMFs exposure played a protective role in DNA damage. The SAR values selected in the present study was based on the $1.6 \mathrm{~W} / \mathrm{kg}$ limit established by the US and the $2.0 \mathrm{~W} / \mathrm{kg}$ standard that is specified by the International Commission on Nonionizing Radiation Protection (ICNIRP) [29]. In addition, the accepted SAR threshold for non-thermal and thermal effects is $4 \mathrm{~W} / \mathrm{kg}$. Thus, the exposure doses of $1 \mathrm{~W} / \mathrm{kg}, 2 \mathrm{~W} / \mathrm{kg}$ and $4 \mathrm{~W} / \mathrm{kg}$ were selected to avoid thermal effects. The present study suggested that $4 \mathrm{~W} / \mathrm{kg}$ was a dangerous value for health.

The increased use of mobile communications results in humans being exposed to higher levels of RF-EMFs. Mobile phones are commonly carried in pockets very close to reproductive organs. In addition, the use of bluetooth may increase exposure to male reproductive organs and change proteomic levels in the male reproductive system [30]. Previous investigations suggested that RF-EMFs exposure may increase DNA damage in human spermatozoa, and decrease semen quality, particularly motility [31]. Similar results have shown that RF-EMFs exposure significantly impacted the integrity of nuclear genomes in male mice [32]. However, the mechanisms underlying mobile phone use-induced male reproductive disorders are unclear. Previous studies have suggested that RF-EMFs may stimulate ROS generation both in vivo [33] and in vitro [34], and the present study confirmed these results. The RF-EMFs used for communications do not have enough energy to directly damage DNA, and it has been suggested that oxidative stress could be a key factor [7]. The results were confirmed in the present study that melatonin could prevent DNA damage through inhibition of ROS production, and the other reports also suggested that melatonin protect DNA damage may be via improving lipid metabolism, except for inhibition of ROS production [35]. Sperm DNA integrity is essential for the accurate transmission of genetic information and production of normal motile spermatozoa, and any form of DNA damage may result in male infertility [36]. Therefore, in terms of male infertility, it is very important to prevent sperm DNA damage due to RF-EMFs exposure.

Autophagy acts as a survival process under environmental stress, maintaining cellular homeostasis by regenerating metabolic precursors and clearing subcellular debris [37]. Previous studies demonstrated that RF-EMFs increased the formation of ROS in spermatozoa 
[9]. ROS are considered to be one of the primary mechanisms involved in the bio-effects mediated by RF-EMFs [38], especially those resulting from acute exposure to the RF-EMFs from mobile phones [39]. It is well-known that the overproduction of ROS can cause severe damage to cellular macromolecules, and ROS production is an important intracellular inducer of autophagy [40]. A previous study indicated that ROS regulate autophagy involved in cell survival in endothelial cells [41]. Previous investigations have shown that ROS can stimulate autophagy via the AMPK signaling pathway which is necessary for controlling cellular autophagy under oxidative stress, and subsequently prevent oxidative injury and dysfunction [42]. Numerous studies have demonstrated that AMPK has the ability to stimulate autophagy by inhibiting mTOR signaling [43]. In accordance with previous studies, when AMPK interference by siRNA was used in the present study, autophagy was suppressed after RF-EMFs exposure. In addition, overexpression of AMPK promoted autophagy.

In response to DNA damage, cells will trigger a series of signaling cascades, and cellular fate is determined by the degree of DNA damage. When DNA damage is reparable and mild, the signaling pathways involved in promoting cell survival will be activated. However, when severe damage is beyond repair, cell death occurs. Thus, autophagy can play a dual role in determining cell fate by two process, not only can it play a protective role, but autophagy can also lead to cell death [44]. Autophagy can induce an adaptive response to protect against chemical mutagens and ionizing radiation [45-48]. This protective role is generally described as an adaptive response and has been well documented in human and animal cells [49]. Blockage of autophagy can result in the accumulation of dysfunctional mitochondria, damaged mitochondrial DNA and an increased rate of apoptotic cell death induced by UV radiation, $900 \mathrm{MHz}$ RF-EMFs exposure or smoking, respectively [50-52]. A previous study suggested that autophagy may play an important role in preventing mouse spermatocytederived cells from apoptotic cell death following exposure to 1, 800-MHz GSM $4 \mathrm{~W} / \mathrm{kg}$ [18]. However, previous studies did not determine the role of autophagy in DNA damage induced by RF-EMFs in mouse spermatocyte-derived cells. In the present study, following inhibition or promotion of autophagy, the results indicated that DNA damage induced by RF-EMFs could be prevented by autophagy in mouse spermatocyte-derived cells.

In conclusion, the present study indicated that autophagy and DNA damage may be activated by RF-EMFs-induced ROS generation. The AMPK/mTOR signaling pathway was involved in RF-EMFs-induced autophagy, and autophagy had a protective role in DNA damage induced by RF-EMFs exposure. These findings provide evidence of the mechanism by which RF-EMFs trigger autophagy and the positive role autophagy plays in the DNA damage response to RF-EMFs treatment.

\section{Abbreviations}

RF-EMFs (Radiofrequency electromagnetic fields); AMPK (AMP-activated protein kinase); TEM (Transmission electron microscopy); ROS (Reactive oxygen species); SAR (Specific absorption rate); GSM (Global System for Mobile Communication); EMFs (Frequency electromagnetic fields).

\section{Acknowledgements}

We thank all the people who helped us in the present study.

This study was supported by Natural Science Foundation of China (No. 81402656), Chongqing Municipal Science and Technology Commission Fundamental Research funded project (No. 2017cstc-jbky-1706), and Beijing Natural Science Foundation (No. 7182011). 


\section{Cellular Physiology Cell Physiol Biochem 2018;48:29-41 \begin{tabular}{ll|l} 
and Biochemistry & $\begin{array}{l}\text { DOI: 10.1159/000491660 } \\
\text { Published online: July 11, } 2018\end{array}$ & $\begin{array}{l}\text { C } 2018 \text { The Author(s). Published by S. Karger AG, Basel } \\
\text { www.karger.com/cpb }\end{array}$ \\
\hline
\end{tabular} \\ Li et al.: Autophagy Prevents DNA Damage}

\section{Disclosure Statement}

The authors report no conflicts of interest. The authors alone are responsible for the content and writing of the paper. The authors declare that they have no financial and personal relationships with other people or organizations that can inappropriately influence their work. There is no professional or other personal interest of any nature or kind in any product, service and/or company.

\section{References}

-1 Yuksel M, Naziroglu M, Ozkaya MO: Long-term exposure to electromagnetic radiation from mobile phones and Wi-Fi devices decreases plasma prolactin, progesterone, and estrogen levels but increases uterine oxidative stress in pregnant rats and their offspring. Endocrine 2016;52:352-362.

-2 Asghari A, Khaki AA, Rajabzadeh A, Khaki A: A review on Electromagnetic fields (EMFs) and the reproductive system. Electron Physician 2016;8:2655-2662.

-3 Sepehrimanesh M, Kazemipour N, Saeb M, Nazifi S: Analysis of rat testicular proteome following 30-day exposure to $900 \mathrm{MHz}$ electromagnetic field radiation. Electrophoresis 2014;35:3331-3338.

4 Sepehrimanesh M, Saeb M, Nazifi S, Kazemipour N, Jelodar G, Saeb S: Impact of 900 MHz electromagnetic field exposure on main male reproductive hormone levels: a Rattus norvegicus model. Int J Biometeorol 2014;58:1657-1663.

-5 Sepehrimanesh M, Azarpira N, Saeb M, Nazifi S, Kazemipour N, Koohi O: Pathological changes associated with experimental 900-MHz electromagnetic wave exposure in rats. Comparative Clinical Pathology 2013;23:1629-1631.

-6 Sepehrimanesh M, Kazemipour N, Saeb M, Nazifi S, Davis DL: Proteomic analysis of continuous 900-MHz radiofrequency electromagnetic field exposure in testicular tissue: a rat model of human cell phone exposure. Environ Sci Pollut Res Int 2017;24:13666-13673.

-7 Friedman J, Kraus S, Hauptman Y, Schiff Y, Seger R: Mechanism of short-term ERK activation by electromagnetic fields at mobile phone frequencies. Biochem J 2007;405:559-568.

-8 Aitken RJ, Curry BJ: Redox regulation of human sperm function: from the physiological control of sperm capacitation to the etiology of infertility and DNA damage in the germ line. Antioxid Redox Signal 2011;14:367-381.

9 De Iuliis GN, Newey RJ, King BV, Aitken RJ: Mobile phone radiation induces reactive oxygen species production and DNA damage in human spermatozoa in vitro. PLoS One 2009;4:e6446.

-10 Liu C, Duan W, Xu S, Chen C, He M, Zhang L, Yu Z, Zhou Z: Exposure to $1800 \mathrm{MHz}$ radiofrequency electromagnetic radiation induces oxidative DNA base damage in a mouse spermatocyte-derived cell line. Toxicol Lett 2013;218:2-9.

-11 Aitken RJ, De Iuliis GN, McLachlan RI: Biological and clinical significance of DNA damage in the male germ line. Int J Androl 2009;32:46-56.

12 Evenson D, Wixon R: Meta-analysis of sperm DNA fragmentation using the sperm chromatin structure assay. Reprod Biomed Online 2006;12:466-472.

13 Towers CG, Thorburn A: Therapeutic Targeting of Autophagy. EBioMedicine 2016;14:15-23.

14 Singh R, Cuervo AM: Autophagy in the cellular energetic balance. Cell Metab 2011;13:495-504.

15 Moore MN, Allen JI, Somerfield PJ: Autophagy: role in surviving environmental stress. Mar Environ Res 2006;62 Suppl:S420-425.

16 Shen Y, Xia R, Jiang H, Chen Y, Hong L, Yu Y, Xu Z, Zeng Q: Exposure to 50Hz-sinusoidal electromagnetic field induces DNA damage-independent autophagy. Int J Biochem Cell Biol 2016;77:72-79.

-17 Kim JH, Yu DH, Huh YH, Lee EH, Kim HG, Kim HR: Long-term exposure to 835 MHz RF-EMF induces hyperactivity, autophagy and demyelination in the cortical neurons of mice. Sci Rep 2017;7:41129.

18 Liu K, Zhang G, Wang Z, Liu Y, Dong J, Dong X, Liu J, Cao J, Ao L, Zhang S: The protective effect of autophagy on mouse spermatocyte derived cells exposure to $1800 \mathrm{MHz}$ radiofrequency electromagnetic radiation. Toxicol Lett 2014;228:216-224. 


\section{Cellular Physiology Cell Physiol Biochem 2018;48:29-41 \begin{tabular}{ll|l} 
DOI: 10.1159/000491660 & $\begin{array}{l}\text { O } 2018 \text { The Author(s). Published by S. Karger AG, Basel } \\
\text { www.karger.com/cpb }\end{array}$
\end{tabular} \\ Li et al.: Autophagy Prevents DNA Damage}

19 Capri M, Scarcella E, Bianchi E, Fumelli C, Mesirca P, Agostini C, Remondini D, Schuderer J, Kuster N, Franceschi C, Bersani F: $1800 \mathrm{MHz}$ radiofrequency (mobile phones, different Global System for Mobile communication modulations) does not affect apoptosis and heat shock protein 70 level in peripheral blood mononuclear cells from young and old donors. Int J Radiat Biol 2004;80:389-397.

20 Ohtani S, Ushiyama A, Maeda M, Hattori K, Kunugita N, Wang J, Ishii K: Exposure time-dependent thermal effects of radiofrequency electromagnetic field exposure on the whole body of rats. J Toxicol Sci 2016;41:655-666.

-21 Kaygisiz SY, Cigerci IH: Genotoxic evaluation of different sizes of iron oxide nanoparticles and ionic form by SMART, Allium and comet assay. Toxicol Ind Health 2017;33:802-809.

22 Jo JR, Park JS, Park YK, Chae YZ, Lee GH, Park GY, Jang BC: Pinus densiflora leaf essential oil induces apoptosis via ROS generation and activation of caspases in YD-8 human oral cancer cells. Int J Oncol 2012;40:1238-1245.

23 Yang W, Huang J, Xiao B, Liu Y, Zhu Y, Wang F, Sun S: Taurine Protects Mouse Spermatocytes from Ionizing Radiation-Induced Damage Through Activation of Nrf2/HO-1 Signaling. Cell Physiol Biochem 2017;44:1629-1639.

-24 Collins QF, Liu HY, Pi J, Liu Z, Quon MJ, Cao W: Epigallocatechin-3-gallate (EGCG), a green tea polyphenol, suppresses hepatic gluconeogenesis through 5'-AMP-activated protein kinase. J Biol Chem 2007;282:30143-30149.

25 Liu H, Lo CM, Yeung OWH, Li CX, Liu XB, Qi X, Ng KTP, Liu J, Ma YY, Lam YF, Lian Q, Chan SC, Man K: NLRP3 inflammasome induced liver graft injury through activation of telomere-independent RAP1/KC axis. J Pathol 2017;242:284-296.

26 Cui Y, Ren L, Li B, Fang J, Zhai Y, He X, Du E, Miao Y, Hua J, Peng S: Melatonin Relieves Busulfan-Induced Spermatogonial Stem Cell Apoptosis of Mouse Testis by Inhibiting Endoplasmic Reticulum Stress. Cell Physiol Biochem 2017;44:2407-2421.

-27 Wang HF, Chang M, Peng TT, Yang Y, Li N, Luo T, Cheng YM, Zhou MZ, Zeng XH, Zheng LP: Exposure to Cadmium Impairs Sperm Functions by Reducing CatSper in Mice. Cell Physiol Biochem 2017;42:44-54.

28 Pi H, Xu S, Reiter RJ, Guo P, Zhang L, Li Y, Li M, Cao Z, Tian L, Xie J, Zhang R, He M, Lu Y, Liu C, Duan W, Yu Z, Zhou Z: SIRT3-SOD2-mROS-dependent autophagy in cadmium-induced hepatotoxicity and salvage by melatonin. Autophagy 2015;11:1037-1051.

29 Hardell L, Sage C: Biological effects from electromagnetic field exposure and public exposure standards. Biomed Pharmacother 2008;62:104-109.

-30 Sepehrimanesh M, Davis DL: Proteomic impacts of electromagnetic fields on the male reproductive system. Comparative Clinical Pathology 2016;26:309-313.

-31 Fejes I, Zavaczki Z, Szollosi J, Koloszar S, Daru J, Kovacs L, Pal A: Is there a relationship between cell phone use and semen quality? Arch Androl 2005;51:385-393.

-32 Aitken RJ, Bennetts LE, Sawyer D, Wiklendt AM, King BV: Impact of radio frequency electromagnetic radiation on DNA integrity in the male germline. Int J Androl 2005;28:171-179.

33 Sepehrimanesh M NS, Saeb M, Kazemipour N: <Effect of $900 \mathrm{MHz}$ radiofrequency electromagnetic field exposure on antioxidant enzymes in serum and testicular tissue of rat.pdf $>$. Online Journal of Veterinary Research 2016;20:8.

34 Lu YS, Huang BT, Huang YX: Reactive oxygen species formation and apoptosis in human peripheral blood mononuclear cell induced by $900 \mathrm{MHz}$ mobile phone radiation. Oxid Med Cell Longev 2012;2012:740280.

-35 Ortiz-Franco M, Planells E, Quintero B, Acuna-Castroviejo D, Rusanova I, Escames G, Molina-Lopez J: Effect of Melatonin Supplementation on Antioxidant Status and DNA Damage in High Intensity Trained Athletes. Int J Sports Med 2017;38:1117-1125.

-36 Agarwal A, Said TM: Role of sperm chromatin abnormalities and DNA damage in male infertility. Hum Reprod Update 2003;9:331-345.

37 Doria A, Gatto M, Punzi L: Autophagy in human health and disease. N Engl J Med 2013;368:1845.

-38 Desai NR, Kesari KK, Agarwal A: Pathophysiology of cell phone radiation: oxidative stress and carcinogenesis with focus on male reproductive system. Reprod Biol Endocrinol 2009;7:114.

-39 Moustafa YM, Moustafa RM, Belacy A, Abou-El-Ela SH, Ali FM: Effects of acute exposure to the radiofrequency fields of cellular phones on plasma lipid peroxide and antioxidase activities in human erythrocytes. J Pharm Biomed Anal 2001;26:605-608. 


\section{Cellular Physiology Cell Physiol Biochem 2018;48:29-41 \begin{tabular}{l|l} 
DOI: 10.1159/000491660 & $\begin{array}{l}\text { O 2018 The Author(s). Published by S. Karger AG, Basel } \\
\text { www.karger.com/cpb }\end{array}$
\end{tabular} \\ Li et al.: Autophagy Prevents DNA Damage}

40 Garg AD, Dudek AM, Ferreira GB, Verfaillie T, Vandenabeele P, Krysko DV, Mathieu C, Agostinis P: ROSinduced autophagy in cancer cells assists in evasion from determinants of immunogenic cell death. Autophagy 2013;9:1292-1307.

41 Tokarz P, Piastowska-Ciesielska AW, Kaarniranta K, Blasiak J: All-Trans Retinoic Acid Modulates DNA Damage Response and the Expression of the VEGF-A and MKI67 Genes in ARPE-19 Cells Subjected to Oxidative Stress. Int J Mol Sci 2016;17:

42 Li X, Zhang X, Zheng L, Kou J, Zhong Z, Jiang Y, Wang W, Dong Z, Liu Z, Han X, Li J, Tian Y, Zhao Y, Yang L: Hypericin-mediated sonodynamic therapy induces autophagy and decreases lipids in THP-1 macrophage by promoting ROS-dependent nuclear translocation of TFEB. Cell Death Dis 2016;7:e2527.

43 Wu T, Wang MC, Jing L, Liu ZY, Guo H, Liu Y, Bai YY, Cheng YZ, Nan KJ, Liang X: Autophagy facilitates lung adenocarcinoma resistance to cisplatin treatment by activation of AMPK/mTOR signaling pathway. Drug Des Devel Ther 2015;9:6421-6431.

44 Zhang D, Tang B, Xie X, Xiao YF, Yang SM, Zhang JW: The interplay between DNA repair and autophagy in cancer therapy. Cancer Biol Ther 2015;16:1005-1013.

45 Cao Y, Xu Q Jin ZD, Zhou Z, Nie JH, Tong J: Induction of adaptive response: pre-exposure of mice to $900 \mathrm{MHz}$ radiofrequency fields reduces hematopoietic damage caused by subsequent exposure to ionising radiation. Int J Radiat Biol 2011;87:720-728.

46 Jiang B, Nie J, Zhou Z, Zhang J, Tong J, Cao Y: Adaptive response in mice exposed to $900 \mathrm{MHz}$ radiofrequency fields: primary DNA damage. PLoS One 2012;7:e32040.

47 Sannino A, Sarti M, Reddy SB, Prihoda TJ, Vijayalaxmi, Scarfi MR: Induction of adaptive response in human blood lymphocytes exposed to radiofrequency radiation. Radiat Res 2009;171:735-742.

48 Sannino A, Zeni O, Romeo S, Massa R, Gialanella G, Grossi G, Manti L, Vijayalaxmi, Scarfi MR: Adaptive response in human blood lymphocytes exposed to non-ionizing radiofrequency fields: resistance to ionizing radiation-induced damage. J Radiat Res 2014;55:210-217.

-49 Jiang B, Zong C, Zhao H, Ji Y, Tong J, Cao Y: Induction of adaptive response in mice exposed to $900 \mathrm{MHz}$ radiofrequency fields: application of micronucleus assay. Mutat Res 2013;751:127-129.

50 Chen LH, Chu PM, Lee YJ, Tu PH, Chi CW, Lee HC, Chiou SH: Targeting protective autophagy exacerbates UVtriggered apoptotic cell death. Int J Mol Sci 2012;13:1209-1224.

-51 Cotan D, Cordero MD, Garrido-Maraver J, Oropesa-Avila M, Rodriguez-Hernandez A, Gomez Izquierdo L, De la Mata M, De Miguel M, Lorite JB, Infante ER, Jackson S, Navas P, Sanchez-Alcazar JA: Secondary coenzyme Q10 deficiency triggers mitochondria degradation by mitophagy in MELAS fibroblasts. FASEB J 2011;25:2669-2687.

52 Monick MM, Powers LS, Walters K, Lovan N, Zhang M, Gerke A, Hansdottir S, Hunninghake GW: Identification of an autophagy defect in smokers' alveolar macrophages. J Immunol 2010;185:5425-5435. 